\title{
Education-related disparities in reported physical activity during leisure-time, active transportation, and work among US adults: repeated cross-sectional analysis from the National Health and Nutrition Examination Surveys, 2007 to 2016
}

\author{
Shaun Scholes ${ }^{1 * \dagger}$ (D) and David Bann ${ }^{2+}$
}

\begin{abstract}
Background: Understanding socioeconomic disparities in physical activity is important, given its contribution to overall population-wide health and to health disparities. Existing studies examining trends in these disparities have focused exclusively on physical activity during leisure-time and have not investigated the potential moderators of socioeconomic disparities in physical activity. Using self-reported data from the US National Health and Nutrition Examination Survey (NHANES) 2007 to 2016 for 29,039 adults aged 20 years and over we examined educationrelated disparities in overall (total) moderate-to-vigorous intensity physical activity, and in its sub-components, recreational (leisure-time) and non-recreational (active transportation and work) activity. We also examined if education-related disparities in physical activity were moderated by age, gender, and race/ethnicity.
\end{abstract}

Methods: Logistic regression models were used to evaluate disparities in physical activity according to education group and their moderation across age, gender, race/ethnicity, and time-period.

Results: Overall activity levels (\% $\geq 150 \mathrm{~min} /$ week) were highest amongst highly educated adults, yet contrasting education-related disparities were found for recreational and non-recreational activities (active transportation and work), favoring the highest- and lowest-educated groups respectively. Within each domain of activity, associations were moderated by age and race/ethnicity, and by gender for work-based activity. The net result was that education-related disparities in total activity were substantially larger in older adults $(P<0.001)$ and amongst women $(P<0.001)$. For example, the estimated difference in the probability of being active in the highest versus the lowest educational groups was $23.1 \%$ (95\% Cl: 19.1, 27.2) amongst those aged $\geq 60$ years, yet $10.8 \%$ (95\% Cl: 7.1, 14.6) amongst those aged 20-39.

Conclusions: Education-related disparities in physical activity persisted from 2007 to 2016. Our results suggest that understanding and addressing these disparities requires assessment of their multiple domains, and identification of the demographic sub-groups for which the disparities are more or less pronounced.

Keywords: Physical activity, Disparities, Socioeconomic, Race/ethnicity

\footnotetext{
*Correspondence: s.scholes@ucl.ac.uk

†Shaun Scholes and David Bann contributed equally to this work.

${ }^{1}$ Health and Social Surveys Research Group; Research Department of Epidemiology and Public Health, University College London, WC1E 6BT, London, UK

Full list of author information is available at the end of the article
}

(c) The Author(s). 2018 Open Access This article is distributed under the terms of the Creative Commons Attribution 4.0 International License (http://creativecommons.org/licenses/by/4.0/), which permits unrestricted use, distribution, and reproduction in any medium, provided you give appropriate credit to the original author(s) and the source, provide a link to the Creative Commons license, and indicate if changes were made. The Creative Commons Public Domain Dedication waiver (http://creativecommons.org/publicdomain/zero/1.0/) applies to the data made available in this article, unless otherwise stated. 


\section{Background}

Monitoring socioeconomic disparities in physical activity is important, given the contribution of physical activity to overall population-wide health and to health disparities [1, 2]. Systematic reviews have documented that socioeconomic disparities in physical activity exist in high-income countries [3-5], and a smaller number of studies showed that these have persisted across time (e.g., from 2000 to 2009 [6] or 1990-2004 [7] in the United States). The investigation of trends thus requires updating using more recently collected data; it may also yield policy-relevant information on whether public health initiatives to increase physical activity (and reduce its disparities) have been successful at the population level. Furthermore, previous studies have used single physical activity outcomes capturing activity in leisure-time [7] or activity in an unspecified domain/s [6]. Current public health surveillance efforts are therefore limited, since activity occurs across multiple domains (e.g., leisure-time, active transportation, or work)-each domain is likely to have different relations to indicators of socioeconomic status (SES) [4], and each may be separate targets of intervention in order to improve overall activity levels. In addition, potential moderators of socioeconomic disparities in physical activity have not been investigated. Age, gender, and race/ethnicity arguably represent the most important non-modifiable characteristics that may moderate socioeconomic disparities in physical activity, and understanding this may be informative for policy development. Such moderation may be domain-specific. Furthermore, it is unknown whether any moderation of socioeconomic disparities in physical activity has changed over the last decade.

We addressed these limitations using the National Health and Nutrition Examination Survey (NHANES), the only study in the United States (US) with comparable and repeated cross-sectional data on physical activity for recreational and non-recreational (active transportation and work) activities over the 10-year period from 2007 to 2016 [8]. We examined whether education-related disparities in physical activity outcomes were moderated by age, gender, and race/ethnicity, and explored trends over time. We hypothesized that the magnitude of education-related disparities observed in physical activity outcomes would differ by domain, and would be moderated by demographic sub-group. We also hypothesized that these disparities may have increased over time due to concurrent larger increases in the prevalence of obesity [9] and the disproportionate impact of the Great Recession of 200709 [10] amongst the lowest educated groups. Education was used as the indicator of SES in the present study, since it remains relevant throughout adulthood, captures possible differences in knowledge about the positive health impacts of physical activity, and tends to have less missing data than indicators such as income. Alternative indicators of SES such as income are also arguably more likely affected by reverse causation or confounding due to ill-health.

\section{Methods}

The study population was adults aged 20 years and older in the five 2-year survey cycles of NHANES between 2007 and $2016(N=29,039)$. NHANES is a repeated cross-se ctional survey, with information on its design, data collection, and sampling provided extensively elsewhere [11, 12]. It uses a four-stage stratified cluster probability sample design to sample the non-institutionalized civilian US population to obtain results that are nationally representative of the US population. Response rates during the study period ranged from 61\% (2015-16) to 79\% (2009-10). The CDC National Center for Health Statistics Research Ethics Review Board approved the NHANES study protocol, and all survey participants provided written, informed consent before completing any questionnaires.

Physical activity data was obtained for persons aged 16 years and older during in-person interviews using an adapted version of the Global Physical Activity Questionnaire (GPAQ) [13] from 2007 to 08 onwards, precluding the assessment of longer-term trends [14]. Briefly, the GPAQ assesses the frequency (number of days per week) and duration (amount of time spent on a typical day) of physical activity undertaken for a minimum of $10 \mathrm{~min}$ for recreational activities (separately for moderate- and vigorous-intensity activities), walking/bicycling for transportation, and work (separately for moderate- and vigorous-intensity activities). Work included both paid and unpaid work, household chores, and yard work; participants were instructed to think of work as "the things that you have to do such as paid or unpaid work, household chores, and yard work." Therefore occupational and domestic physical activity could not be assessed separately. For the active transportation domain, information on all walking and bicycling are collected; however, these activities are not differentiated nor is the intensity level assessed [13]. As in other studies [15], walking/bicycling for transportation was assumed in our study to be of moderate intensity. This is in accordance with the WHO GPAQ analysis guide which assigns a metabolic equivalent of task (MET) of 4 to the active transportation domain [16]. The most extensive study of the validity and reliability of the GPAQ was conducted among 2657 adults from nine diverse countries, particularly among countries with lower educational levels [17]. Criterion validity was assessed using objective motion monitors, either a pedometer or accelerometer. Test-retest reliability was examined using a 3to 7-day time gap between data collection. The results showed that the GPAQ performed well. The level of pooled criterion validity (from pedometer step counts) 
for the GPAQ assessed total physical activity score was fair $(r=0.31)$, but was lower for total vigorous-intensity physical activity compared with average vigorous activity counts/day from an accelerometer $(r=0.23$ to $r=0.26)$. Test-retest reliability data produced good-to-excellent results, indicating a high level of repeatability between administrations $(r=0.67-0.81)$ [17].

We calculated the minutes/week spent in moderateand vigorous-intensity activities in each of the three domains (recreational; active transportation; work). We also calculated an overall (total) measure of aerobic activity, comprising minutes/week spent in moderate-to-vigorous intensity physical activity (MVPA) across all domains. Participants were classed as aerobically active if they reached the recommended $150 \mathrm{~min} /$ week of moderate-intensity physical activity, $75 \mathrm{~min} /$ week of vigorous-intensity physical activity, or a combination of the two [18]. The equivalent binary indicator was calculated for each domain.

Highest educational attainment was obtained among adults aged 20 years and older, and was categorized as follows: less than high school $(\leq 11$ th grade, but includes 12th grade with no diploma); high school diploma/general education development (GED) test; some college or associate (AA) degree; and college graduate or higher. Categories were created for age (20-39, 40-59, $\geq 60$ years), and race/ethnicity (Non-Hispanic white, Hispanic/Mexican, Non-Hispanic black, other). Participants reported race/ethnicity from a list provided to them that included an open-ended response.

\section{Statistical analyses}

Our analyses were limited to $N=29,201$ adults aged 20 years and older, consistent with the reference age of the questions used to measure educational attainment. 39 adults $(0.1 \%)$ were excluded from our complete-case analyses due to missing education data; 123 adults with valid education data were excluded due to missing physical activity data $(0.4 \%)$. This resulted in an analytical sample of $N=29,039$ adults with valid data for educational attainment and each physical activity indicator.

Highest educational attainment was cross-tabulated with age, gender, and race/ethnicity. Analyses were conducted separately for each domain and for overall (total) MVPA. Bivariate analysis consisted of the chi-square $x^{2}$ test for differences in the proportion of adults categorized as active ( $\geq 150 \mathrm{~min} /$ week) by age, gender, and race/ethnicity. Regression analyses were conducted on the data pooled over the five, 2-year NHANES survey cycles to assess potential independent and interactive relations of educational group, gender, age, and race/ethnicity to each physical activity indicator. Logistic regression was used since the distribution of the outcomes (inclusion of zeros and right-skew) precluded modelling the minutes/week spent active in continuous form [19, 20]. To explore possible moderation of the associations between education and physical activity we included each two-way interaction term (education $\times$ gender; education $\times$ age; education $\times$ race/ethnicity), in addition to the first-order terms of education, gender, age, race/ethnicity, and survey cycle. These variables were entered in the models as categorical terms with the following reference categories: education (less than high school); age (20-39 years); gender (male); and race/ethnicity (Non-Hispanic white). Wald tests were used to formally test the two-way interaction terms. Estimates of association are presented on the absolute scale since differences in activity prevalence between groups may distort comparisons of effect sizes expressed on the relative scale (e.g., through odds ratios) - an identical absolute difference in activity prevalence would have a larger odds ratio if activity prevalence was lower [21]. Our approach is consistent with calls for increasing use of absolute difference measures in public health research [22].

Prevalence estimates and 95\% confidence intervals (95\% CI) were calculated using model-based predictive margins [23]. Firstly, the proportion of adults categorized as active was estimated for each educational group after adjustment for age, gender, and race/ethnicity. Secondly, estimates for each moderator by educational group were mutually-adjusted (e.g., \% active for each age category by education was adjusted for gender and race/ ethnicity). Estimates for subgroups included adults classified in the 'other' race/ethnic group but are not reported separately given their small sample size and likely heterogeneity. To facilitate interpretation of the possible moderation of education-related disparities in physical activity, we show graphically the absolute difference in the estimated probability of being active for each educational group versus the reference (less than high school) for each level of the moderator, after mutual adjustment for the other variables.

To examine if physical activity disparities changed across time (2007 to 2016), we tested two-way interaction terms between education and year (linear term). Threeway interaction terms were also tested to examine if changes across year differed in demographic sub-groups (education $\times$ gender $\times$ year; education $\times$ age $\times$ year; education $\times$ race/ethnicity $\times$ year). The NHANES survey cycle (year) was entered into the models as a continuous variable (range 1-5).

All estimates were weighted using the 2-year sample weights provided by NHANES to account for the differential sample selection, survey nonresponse and post-stratification adjustments. Analyses were performed in Stata, version 15.0 (StataCorp LP, College Station, Texas).

\section{Sensitivity analyses}

To investigate if changes in the distribution of education across time affected our findings, we repeated our 
analyses by converting the categories of highest educational attainment into a ridit score. Estimates from the resulting model can be interpreted as the Slope Index of Inequality [24]. To examine if the analyses were sensitive to the specific cut-point used for overall MVPA, alternative cut-points were used $(\geq 60, \geq 90$ and $\geq 120 \mathrm{~min} /$ week in overall MVPA).

\section{Results}

Age, gender and race/ethnicity were strongly associated with highest educational attainment: the proportion of adults achieving some college / associate degree or higher was lowest amongst older adults, and was highest amongst women and Non-Hispanic whites ( $P$ for $X^{2}$-tests all $<0.001$; see Additional file 1).

\section{Leisure-time}

The proportion of adults categorized as active $(\geq 150 \mathrm{~min} /$ week) in the leisure-time domain differed by age, gender and race/ethnicity: activity levels were highest amongst younger adults, men, and Non-Hispanic whites ( $P$ for $X^{2}$-tests all $<0.001$; see Additional file 2 ).

Activity was highest amongst highly-educated adults, similarly from 2007 to 2016 (education $\times$ year: $P=0.908$ ) (Table 1). However, the magnitude of these education-related disparities was largest amongst younger adults (education $\times$ age: $P=0.016)$ and Non-Hispanic whites (education $\times$ ethnicity: $P=0.002$ ) (Table 1 and Fig. 1). Differences in the magnitude of education-related disparities according to race/ethnicity were particularly pronounced. For example, the estimated difference in the probability of spending $\geq 150 \mathrm{~min} /$ week in leisure-time activity between adults in the highest versus the lowest educational groups was $38.1 \%$ (95\% CI: 34.8, 41.4) amongst Non-Hispanic whites and $23.9 \%$ (95\% CI: 19.3, 28.4) amongst Hispanic/ Mexicans; a 14.2\%-point or over 1.5-fold difference (Fig. 1). Moderation of these education-related disparities persisted over the 10-year study period (education $\times$ year $\times$ demographic sub-group: $P$ all $>0.05$ ).

\section{Active transportation}

Levels of active transportation ( $\geq 150 \mathrm{~min} /$ week) differed by age, gender and race/ethnicity: activity levels were highest in younger adults and in men, and were lowest amongst Non-Hispanic whites $\left(P\right.$ for $\mathrm{X}^{2}$-tests all $<0.001$; Additional file 2).

Amongst the educational groups, active transportation was highest in lower educated adults, similarly from 2007 to 2016 (education $\times$ year: $P=0.111$ ). Education-related disparities were weak in magnitude. For example, the estimated probability of spending $\geq 150 \mathrm{~min} /$ week in active transportation was $16.4 \%$ (95\% CI: 14.5, 18.2) amongst adults with less than high-school education compared with $12.7 \%$ (95\% CI:
$11.2,14.2)$ of college graduates or higher (Table 1). Education-related disparities in active transportation were larger amongst younger- and middle-aged adults (education $\times$ age: $P=0.006$ ), and amongst Hispanic/ Mexicans and Non-Hispanic blacks (education $\times$ ethnicity: $P<0.001$ ), but showed no difference by gender (education $\times$ gender: $P=0.737$ ). However, these associations did not systematically differ over the 10-year study period (education $\times$ year $\times$ demographic sub -group: $P$ all $>0.10$ ).

\section{Work}

The proportion of adults classed as active in the work domain ( $\geq 150 \mathrm{~min} /$ week) differed by age, gender and race/ethnicity: activity levels were highest amongst younger adults, men, and Non-Hispanic whites $(P$ for $\mathrm{x}$ 2-tests all $<0.001$; Additional file 2).

Highest educational attainment was non-linearly related to work-based physical activity-it was highest amongst adults with high school or some college education, and was lowest amongst college graduates or higher. These disparities did not systematically differ from 2007 to 2016 (education $\times$ year: $P=0.519$ ).

Education-related disparities in work-based activity were larger amongst younger compared with older adults (education $\times$ age: $P<0.001$ ); men compared with women (education $\times$ gender: $P<0.001$ ); and amongst Non-Hispanic whites (education $\times$ ethnicity: $P=0.021$; Table 1 and Fig. 1). For example, the estimated difference in the probability of spending $\geq 150 \mathrm{~min} /$ week in work-based activity between adults in the lowest versus the highest educational groups was $18.0 \%$ (95\% CI: 14.3, 21.7) amongst men and 3.3\% (95\% CI: 0.0, 6.5) amongst women; a $14.7 \%$-point or over 5-fold difference (Fig. 1). However, these associations did not systematically differ over the 10-year study period (education $\times$ year $\times$ demographic sub-group: $P$ all $>0.10$ ).

\section{Overall (total) MVPA}

The proportion of adults classed as aerobically active (MVPA $\geq 150 \mathrm{~min} /$ week) across all domains differed by age, gender and race/ethnicity: activity levels were highest amongst younger adults, men, and Non-Hispanic whites ( $P$ for $\chi^{2}$-tests all $<0.001$; Additional file 2 ).

Activity levels were highest amongst highly-educated adults, similarly from 2007 to 2016 (education $\times$ year: $P=0.440$ ). The estimated probability of spending $\geq 150 \mathrm{~min} /$ week in MVPA was $68.6 \%$ (95\% CI: 66.9, 70.3 ) amongst college graduates or higher compared with $54.7 \%$ (95\% CI: 52.7, 56.8) of adults with less than high-school education (Table 1). However, the magnitude of these education-related disparities were larger amongst older compared with younger adults (education $\times$ age: $P<0.001$ ), and amongst women 
Table 1 Probabilities of spending $\geq 150$ min/week in moderate-to-vigorous physical activities amongst 29,039 US adults aged $\geq 20$ years

\begin{tabular}{|c|c|c|c|c|c|c|c|c|c|}
\hline \multirow[t]{3}{*}{ Physical activity domain, education group } & \multirow{3}{*}{$\begin{array}{l}\text { All } \\
\%(S E)\end{array}$} & \multicolumn{3}{|c|}{ Age group } & \multicolumn{2}{|l|}{ Gender } & \multicolumn{3}{|c|}{ Race/ethnicity } \\
\hline & & \multirow{2}{*}{$\begin{array}{l}20-39 \\
\%^{\mathrm{a}}(\mathrm{SE})\end{array}$} & \multirow{2}{*}{$\begin{array}{l}40-59 \\
\%^{a}(\mathrm{SE})\end{array}$} & \multirow{2}{*}{$\begin{array}{l}\geq 60 \\
\%^{a}(S E)\end{array}$} & \multirow{2}{*}{$\begin{array}{l}\text { Men } \\
\%^{\mathrm{a}}(\mathrm{SE})\end{array}$} & \multirow{2}{*}{$\begin{array}{l}\text { Women } \\
\%^{\mathrm{a}} \text { (SE) }\end{array}$} & \multirow{2}{*}{$\begin{array}{l}\text { White } \\
\%^{a}(\text { SE) }\end{array}$} & \multirow{2}{*}{$\begin{array}{l}\text { Hispanic } \\
\%^{a}(\mathrm{SE})\end{array}$} & \multirow{2}{*}{$\begin{array}{l}\text { Black } \\
\%^{a}(\mathrm{SE})\end{array}$} \\
\hline & & & & & & & & & \\
\hline \multicolumn{10}{|l|}{ Leisure-time } \\
\hline$<11$ th grade & $18.4(0.8)$ & $26.5(1.4)$ & $15.4(1.1)$ & $10.9(0.8)$ & $22.1(1.0)$ & $14.9(1.0)$ & $17.2(1.2)$ & $20.8(1.0)$ & $19.1(1.1)$ \\
\hline High school & $29.7(0.9)$ & $37.4(1.3)$ & $28.2(1.4)$ & $21.1(1.4)$ & $34.3(1.1)$ & $25.5(1.1)$ & $30.6(1.2)$ & $28.6(1.4)$ & $28.3(1.3)$ \\
\hline Some college & $36.7(0.9)$ & $48.4(1.3)$ & $31.4(1.4)$ & $28.0(1.3)$ & $41.5(1.1)$ & $32.3(1.1)$ & $37.7(1.1)$ & $34.9(1.5)$ & $35.0(1.1)$ \\
\hline College graduate or higher & $51.9(1.0)$ & $60.8(1.3)$ & $50.9(1.4)$ & $40.6(1.6)$ & $55.4(1.1)$ & $48.6(1.4)$ & $55.3(1.2)$ & $44.6(2.1)$ & $46.0(1.6)$ \\
\hline$P$ education $x$ year & 0.908 & & & & & & & & \\
\hline$P$ education $\times$ demographic group & & 0.016 & & & 0.253 & & 0.002 & & \\
\hline$P$ education $\mathrm{x}$ demographic group $\mathrm{x}$ year & & 0.341 & & & 0.384 & & 0.535 & & \\
\hline \multicolumn{10}{|l|}{ Active transportation } \\
\hline$<11$ th grade & $16.4(0.9)$ & $19.7(1.3)$ & $17.6(1.4)$ & $9.6(0.7)$ & $18.4(1.1)$ & $14.5(1.0)$ & $14.7(1.2)$ & $18.3(1.4)$ & $19.3(1.3)$ \\
\hline High school & $10.9(0.7)$ & $13.0(1.0)$ & $11.1(0.9)$ & $7.5(0.8)$ & $12.8(0.8)$ & $9.2(0.8)$ & $9.1(0.8)$ & $11.5(1.2)$ & $16.2(1.1)$ \\
\hline Some college & $13.2(0.7)$ & $17.2(1.3)$ & $11.0(0.8)$ & $10.4(0.9)$ & $15.5(0.8)$ & $11.0(0.8)$ & $12.4(0.9)$ & $15.4(1.0)$ & $13.8(1.1)$ \\
\hline College graduate or higher & $12.7(0.8)$ & $16.5(1.4)$ & $10.9(0.8)$ & $10.0(1.1)$ & $14.3(0.8)$ & $11.2(0.9)$ & $13.4(1.0)$ & $11.5(1.3)$ & $9.6(0.9)$ \\
\hline$P$ education $x$ year & 0.111 & & & & & & & & \\
\hline$P$ education $\times$ demographic group & & 0.006 & & & 0.737 & & $<0.001$ & & \\
\hline$P$ education $x$ demographic group $x$ year & & 0.103 & & & 0.168 & & 0.334 & & \\
\hline \multicolumn{10}{|l|}{ Work } \\
\hline$<11$ th grade & $36.9(1.0)$ & $47.3(1.7)$ & $39.3(1.5)$ & $19.0(1.1)$ & $46.0(1.4)$ & $28.3(1.3)$ & $41.5(1.4)$ & $31.1(1.1)$ & $29.0(1.3)$ \\
\hline High school & $41.0(1.0)$ & $48.7(1.5)$ & $43.5(1.5)$ & $26.6(1.7)$ & $51.3(1.1)$ & $31.4(1.3)$ & $44.6(1.3)$ & $35.5(1.5)$ & $34.5(1.4)$ \\
\hline Some college & $40.6(0.8)$ & $48.1(1.1)$ & $41.2(1.4)$ & $29.3(1.3)$ & $49.2(1.1)$ & $32.6(0.9)$ & $43.2(1.0)$ & $37.0(1.5)$ & $35.0(1.3)$ \\
\hline College graduate or higher & $26.5(0.8)$ & $28.2(1.4)$ & $25.2(1.1)$ & $26.0(1.6)$ & $28.1(1.5)$ & $25.1(0.9)$ & $27.9(1.1)$ & $26.2(1.9)$ & $24.8(1.5)$ \\
\hline$P$ education $x$ year & 0.519 & & & & & & & & \\
\hline$P$ education $\times$ demographic group & & $<0.001$ & & & $<0.001$ & & 0.021 & & \\
\hline$P$ education $\mathrm{x}$ demographic group $\mathrm{x}$ year & & 0.951 & & & 0.633 & & 0.497 & & \\
\hline \multicolumn{10}{|l|}{ Overall (total) MVPA } \\
\hline$<11$ th grade & $54.7(1.0)$ & $67.4(1.4)$ & $56.8(1.5)$ & $33.8(1.3)$ & $63.1(1.1)$ & $47.0(1.4)$ & $56.0(1.4)$ & $53.0(1.4)$ & $50.3(1.5)$ \\
\hline High school & $60.3(0.9)$ & $70.4(1.2)$ & $61.5(1.5)$ & $44.3(1.6)$ & $69.9(0.9)$ & $51.5(1.4)$ & $62.6(1.1)$ & $55.7(1.8)$ & $55.6(1.2)$ \\
\hline Some college & $65.1(0.8)$ & $75.4(1.1)$ & $63.4(1.3)$ & $52.8(1.4)$ & $72.8(1.0)$ & $58.0(1.1)$ & $66.6(1.0)$ & $62.8(1.5)$ & $60.8(1.3)$ \\
\hline College graduate or higher & $68.6(0.9)$ & $78.2(1.2)$ & $67.0(1.2)$ & $57.0(1.6)$ & $73.1(1.1)$ & $64.5(1.2)$ & $71.7(1.1)$ & $63.0(2.2)$ & $62.3(1.6)$ \\
\hline$P$ education $x$ year & 0.440 & & & & & & & & \\
\hline$P$ education $\times$ demographic group & & $<0.001$ & & & $<0.001$ & & 0.222 & & \\
\hline$P$ education $x$ demographic group $x$ year & & 0.185 & & & 0.793 & & 0.494 & & \\
\hline
\end{tabular}

Abbreviations: SE standard error

a Prevalence estimates are mutually adjusted (e.g., estimates for age group by education strata adjusted for gender and ethnicity). Hispanic also includes Mexican

compared with men (education $\times$ gender: $P<0.001$; Table 1 and Fig. 1). For example, the estimated difference in the probability of being aerobically active between adults in the highest versus the lowest educational groups was $23.1 \%$ (95\% CI: 19.1, 27.2) amongst those aged $\geq 60$ years, and $10.8 \%$ (95\% CI: 7.1 , 14.6) amongst those aged 20-39 (Fig. 1); a $12.3 \%$-point or over 2.1-fold difference. The corresponding difference was $17.5 \%$ (95\% CI: $13.7,21.3)$ amongst women, and $10.0 \% \quad(95 \%$ CI: $7.2, \quad 12.7)$ amongst men (Fig. 1).

\section{Sensitivity analyses}

Accounting for the change in the distribution of educational attainment over the 10-year period by using the SII yielded similar findings (see Additional file 3 and Additional file 4). Findings were also similar when using alternative cut-off points for classifying participants as 


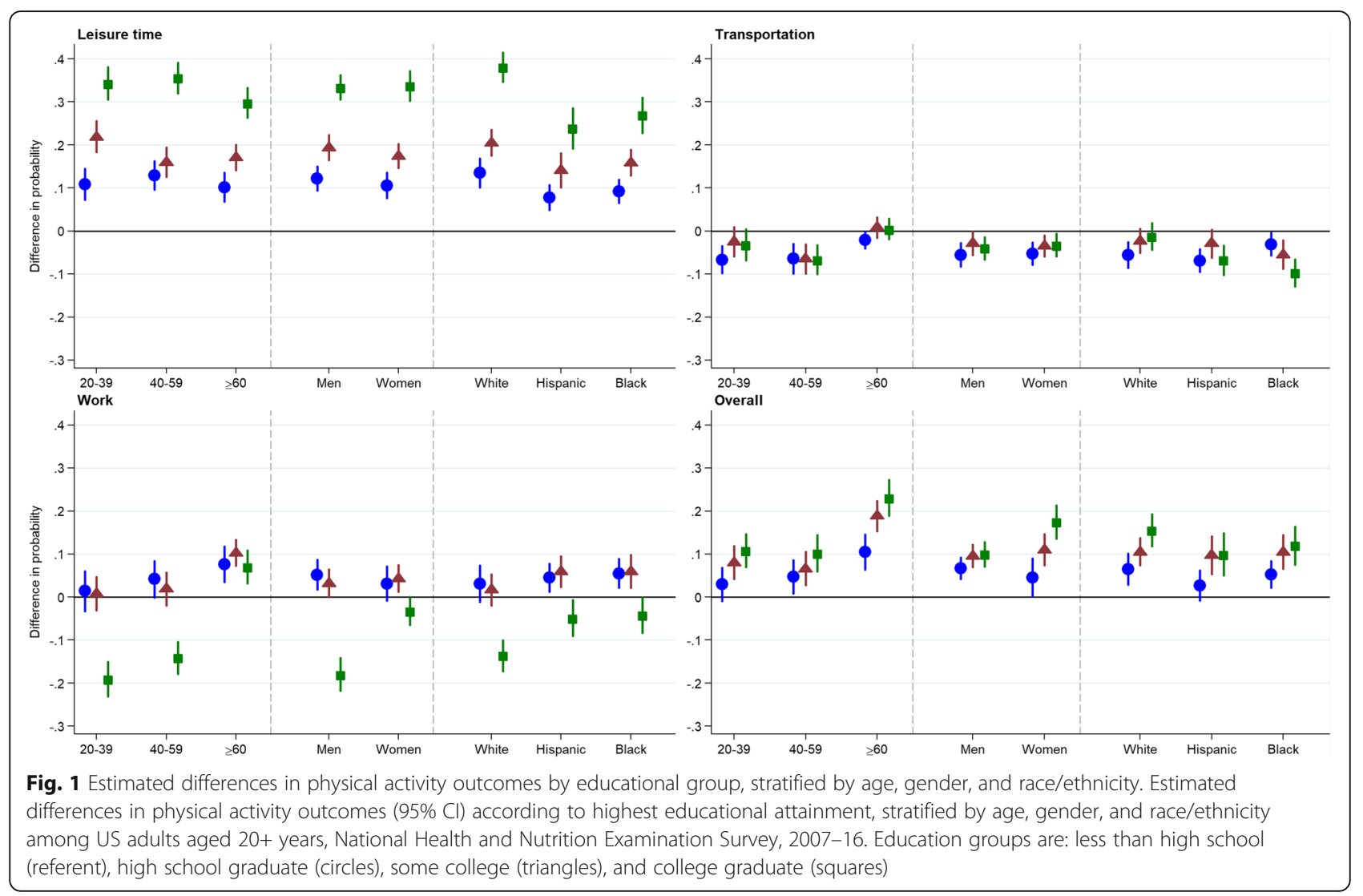

sufficiently active $(\geq 60, \geq 90$ and $\geq 120 \mathrm{~min} /$ week in overall MVPA; see Additional file 5).

\section{Discussion}

Using nationally-representative data from the US, we found that levels of active participation in moderate-to-vigorous intensity physical activity across all domains were highest amongst highly-educated adults. However, the direction and the magnitude of education-related disparities differed by domain. Amongst highly-educated adults, active participation was higher for leisure-time activities, but lower for the active transportation and work domains. The magnitude of these disparities was in some cases greatly moderated by age, gender, and race/ethnicitymagnitudes of disparity between the highest- and lowest-educated groups differed by up to 5 -fold between these sub-groups. The net result of this moderation was that overall (total) activity disparities according to education group were larger in older adults and amongst women.

Our findings are in agreement with the few studies which have investigated how education-related disparities in leisure-time physical activity change across time $[6,7]$-these showed persisting inequalities (in descriptive terms) from 2000 to 2009 and (in relative terms) from 1990 to 2004 [7]. We add to previous findings by providing a detailed and contemporaneous assessment of physical activity disparities, and documenting their persistence up to 2016. Our analysis showed contrasting disparities for recreational and non-recreational physical activity (active transportation and work), yet the net result showed that highly-educated adults had higher overall levels of aerobic physical activity than their lowereducated counterparts.

We also documented the moderation of education-related disparities in physical activity by age and race/ethnicity in each domain, and by gender for work-based activity. Our findings suggest that the intermediary drivers of such disparities-differences in financial resources [3, 4], health status [25], psychological or cultural characteristics [25, 26], and environmental conditions [25, 27, 28]may differ across these demographic groups and that these differences exist within the same level of educational attainment [29] which in turn moderates the magnitude of the disparities in physical activity.

Education-related disparities in leisure-time activity varied by race/ethnicity - this was driven by the substantially higher prevalence of recreational activity amongst Non-Hispanic white college graduates. Three plausible mechanisms may explain this finding. First, racial/ethnic disparities in other socioeconomic factors which exist within the same level of educational attainment may 
affect levels of leisure-time activity. For example, income and wealth returns to college education have been shown to be larger amongst whites [30,31], potentially leading to better access and affordability for their leisure-time participation than those experienced by college graduates in other racial/ethnic groups [32]. Second, racial/ethnic disparities in health also exist within the same level of education attainment [33] — as such, the higher leisure-time activity participation amongst NonHispanic white college graduates may also be partially attributable to a lower prevalence of activity-limiting health conditions (including mobility disability). Third, built environmental factors may also play a role-factors which influence the opportunities to undertake recreational activity (e.g., neighborhood safety, public green space availability) may impact on activity participation, and due to segregation differ by race/ethnicity even amongst persons within the same education group [34-38].

Education-related disparities in leisure-time activity were also marginally larger amongst younger compared with older adults. Younger highly-educated adults may be more active in sports and other recreational activities than their highly-educated older counterparts, potentially due to differences in lifestyle aspirations, physical health, or the effectiveness of public health campaigns [39].

Disparities in active transportation, favoring the lowesteducated groups, possibly reflect fewer financial resources for car ownership [40]. Education-related disparities in active transportation also differed by age. Among persons aged 20-39, active transportation was highest amongst the lowest-educated; among persons aged $\geq 60$, active transportation was marginally higher amongst college graduates. Disparities also differed by race/ethnicitywhile active transportation was lowest amongst all college graduates, it was especially low amongst Non-Hispanic blacks. Further work is required to understand the extent to which the education-related disparities in active transportation (e.g., walking and bicycling) found in our study are driven by policy modifiable factors-while commute distances are challenging to modify, modifiable barriers to active transportation may include psychological factors such as neighborhood safety [41], or knowledge/response to public health messages highlighting the health benefits of active travel.

Disparities in work-based physical activity, which for the purposes of the present study included 'paid or unpaid work', 'household chores' and 'yard work', differed by age, gender, and race/ethnicity-levels of work-based physical activity were higher amongst the lowest-educated groups, and these differences were larger amongst younger adults, men, and Non-Hispanic whites. These differences are likely to be partly attributable to differences in the distribution of physically active occupations. Engagement in strenuous job-related activities and household chores are more likely to be undertaken by adults with low levels of educational attainment [42], who are also male and of younger age. Amongst the lower-educated groups, the higher levels of work-based activity for Non-Hispanic whites may reflect racial/ethnic differences in employment levels during and post the Great Recession $[43,44]$ rather than differences in levels of work-based physical activity per se.

Strengths of our study include the use of NHANES data which enables nationally-representative inference, and a more detailed investigation of education-related disparities across multiple domains of physical activity than in previous studies, or in alternative datasets [8]. Although we demonstrated that education-related disparities differ across the leisure-time, active transportation, and work domains, we were unable to examine more detailed types of activities which may be of particular interest. For example, education-related disparities may be largest for formal leisure-time activities that require greater financial resources to undertake. The questionnaire used (GPAQ) does not capture information on the level of intensity for walking/bicycling for transportation, nor separate these different activities; this may be a useful distinction to make in future studies, given the potentially different determinants of these activities.

These data also enabled investigation of the moderation of education-related disparities in physical activity according to age, gender, and race/ethnicity. However, while NHANES is a comparatively large sample, it is potentially underpowered to detect interaction terms which typically require very large sample sizes $[45,46]$. Our study is unlikely therefore to provide definitive evidence on the presence of modest yet health-impacting edu cation-related disparities in physical activity, and their change over time, across age, gender, or racial/ethnic sub-groups. Other factors which may plausibly moderate physical activity disparities include area of residence, which is likely to impact on both physical activity and economic opportunity [34-38, 47].

The use of identical instruments over five, 2-year NHANES survey cycles enabled the investigation of trends across time, though the availability of comparable data limited the timespan of investigation from 2007 onwards [14]. Reassuringly, we found that results were robust to the use of different cut-offs for classifying overall (total) moderate-to-vigorous intensity physical activity, and the use of the Slope Index of Inequality to account for differences in the distribution of educational attainment across time. However, as in all studies examining trends in disparities, interpretation may be affected by changes in the selection of individuals into the different educational groups over the study period [48]. Due to 
differences in selection and potential causal effects, results may differ when using alternative indicators of socioeconomic status-this warrants future investigation.

Self-reported physical activity is subject to recall and desirability biases, which may lead to the misclassification of activity status [49, 50]. Such misclassification may differ by education and/or demographic sub-group, potentially upwardly or downwardly biasing our estimates of disparities in physical activity. Furthermore, differences in the perception of physical activity questions across demographic sub-groups (e.g., in what constitutes 'moderate' or 'vigorous' activity) [51] might also lead to artefactual differences in the magnitude of physical activity disparities. Investigation of trends over time in objectively measured physical activity may be valuable in future monitoring efforts, although this may be challenging since activity monitors do not currently capture data on activity domain, and current public health guidelines for aerobic activity are based on self-reported data.

Finally, causation cannot be straightforwardly inferred from these observational data. Specifically, while classifying participants according to educational attainment may be beneficial-alternative indicators such as income and occupation may be more likely affected by reverse causation [52] or confounding due to ill health-education-related disparities in physical activity may be attributable to other correlated socioeconomic factors, or preceding parental characteristics which may influence both educational attainment and physical activity levels.

Notwithstanding these caveats, our findings may have implications for both policy and related research. First, our finding documenting the persistence of educationrelated disparities in leisure-time physical activity over the past 10 years suggests that previous policies have not been sufficient, and that additional policy initiatives are required. Second, our findings suggest that in order to reduce disparities in physical activity, there may be sub-groups of the population that may benefit most from intervention-those in which the education-related disparities were largest. Such initiatives may thereby indirectly lead to a narrowing of physical activity disparities (and thereby health disparities) by age, gender, and race/ethnicity. Finally, our findings highlight the importance of considering the domain-specific nature of physical activity disparities. The contrasting disparities for recreational and non-recreational physical activity (active transportation and work), favoring the highestand lowest-educated groups respectively, are especially worrisome as it is increasingly recognized that whilst taking part in recreational activities is beneficial for physical- and mental-health, high levels of involvement in occupational physical activity can be detrimental for health [53-55].

\section{Conclusions}

In conclusion, the large education-related disparities in recreational activity, in favor of the highest-educated groups, outweighed the opposite pattern for non-recreational activities (active transportation and work). Our results suggest that addressing socioeconomic disparities in physical activity requires the assessment of multiple domains of activity, and identification of the different demographic sub-groups for which these disparities are more or less pronounced. These findings should be considered in the future monitoring of socioeconomic disparities in physical activity or of other health-related outcomes, and in the identification of sub-groups that would benefit most from targeted interventions.

\section{Additional files}

Additional file 1: Highest educational attainment by demographic subgroups (age, gender, and race/ethnicity). (DOCX $41 \mathrm{~kb}$ )

Additional file 2: Activity levels ( $\geq 150 \mathrm{~min} /$ week) by demographic subgroups (age, gender, and race/ethnicity). (DOCX 42 kb)

Additional file 3: Differences in activity levels by demographic subgroups (age, gender, and race/ethnicity) using the Slope Index of Inequality. (DOCX $23 \mathrm{~kb}$ )

Additional file 4: Differences in activity levels by demographic subgroups (age, gender, and race/ethnicity) using the Slope Index of Inequality. (TIF $118 \mathrm{~kb}$ )

Additional file 5: Estimated differences in \% active using different cutoffs ( $\geq 60, \geq 90$ and $\geq 120 \mathrm{~min} /$ week in overall MVPA) by educational group, stratified by age, gender, and race/ethnicity. (TIF 136 kb)

\section{Funding}

DB is supported by the Economic and Social Research Council (grant numbers ES/M008584/1 and ES/M001660/1) and The Academy of Medical Sciences / Wellcome Trust ("Springboard Health of the Public in 2040" award: HOP001/1025). The funders had no role in study design, data collection and analysis, decision to publish, or preparation of the manuscript.

Availability of data and materials

NHANES data are available on the CDC NHANES website (https:// wwwn.cdc.gov/nchs/nhanes). Statistical code is available from the corresponding author (email: s.scholes@ucl.ac.uk).

\section{Authors' contributions}

SS and DB jointly contributed to the design of the study (including the analytical strategy), its implementation, quality assurance, and in the writing of all sections of the text. All authors have read and approved the final manuscript.

\section{Ethics approval and consent to participate}

The CDC National Center for Health Statistics Research Ethics Review Board approved the NHANES study protocol, and all survey participants provided written, informed consent before completing any questionnaires.

\section{Consent for publication}

Not applicable.

\section{Competing interests}

The authors declare that they have no competing interests.

\section{Publisher's Note}

Springer Nature remains neutral with regard to jurisdictional claims in published maps and institutional affiliations. 


\section{Author details}

'Health and Social Surveys Research Group; Research Department of Epidemiology and Public Health, University College London, WC1E 6BT, London, UK. ${ }^{2}$ Centre for Longitudinal Studies, University College London Institute of Education, London, UK.

Received: 29 January 2018 Accepted: 17 July 2018

Published online: 28 July 2018

\section{References}

1. Stringhini S, Sabia S, Shipley M, Brunner E, Nabi H, Kivimaki M, et al. Association of socioeconomic position with health behaviors and mortality. JAMA. 2010;303:1159-66.

2. Laaksonen M, Talala K, Martelin T, Rahkonen O, Roos E, Helakorpi S, et al. Health behaviours as explanations for educational level differences in cardiovascular and all-cause mortality: a follow-up of 60000 men and women over 23 years. Eur J Pub Health. 2008;18:38-43.

3. Gidlow $\mathrm{C}$, Johnston $\mathrm{LH}$, Crone D. A systematic review of the relationship between socio-economic position and physical activity. Health Educ J. 2006 65:338-67.

4. Beenackers MA, Kamphuis CB, Giskes K, Brug J, Kunst AE, Burdorf A, et al Socioeconomic inequalities in occupational, leisure-time, and transport related physical activity among European adults: a systematic review. Int J Behav Nutr Phys Act. 2012;9:116.

5. Elhakeem A, Cooper R, Bann D, Hardy R. Childhood socioeconomic position and adult leisure-time physical activity: a systematic review. Int J Behav Nutr Phys Act. 2015;12:92

6. Bleich SN, Jarlenski MP, Bell CN, LaVeist TA. Health inequalities: trends, progress, and policy. Annu Rev Public Health. 2012;33:7-40.

7. Harper S, Lynch J. Trends in socioeconomic inequalities in adult health behaviors among U.S. states, 1990-2004. Public Health Rep. 2007;122:177-89.

8. Keadle SK, McKinnon R, Graubard BI, Troiano RP. Prevalence and trends in physical activity among older adults in the United States: a comparison across three national surveys. Prev Med. 2016;89:37-43.

9. An R. Educational disparity in obesity among US adults, 1984-2013. Ann Epidemiol. 2015;25:637-42.

10. Wang $\mathrm{H}$, Wang $\mathrm{C}$, Halliday $\mathrm{TJ}$. Health and health inequality during the great recession: evidence from the PSID. Econ Hum Biol. 2018;29:17-30.

11. Paulose-Ram R, Burt V, Broitman L, Ahluwalia N. Overview of Asian American data collection, release, and analysis: National Health and Nutrition Examination Survey 2011-2018. Am J Public Health. 2017;107:916-21.

12. Johnson CL, Paulose-Ram R, Ogden $C L$, et al. National Health and Nutrition Examination Survey: Analytic guidelines, 1999-2010. National Center for Health Statistics. Vital Health Stat Series 2. 2013;161.

13. Armstrong T, Bull F. Development of the World Health Organization Globa Physical Activity Questionnaire (GPAQ). J Public Health. 2006;14(2):66-70.

14. Bassett DR, Lee IM. Trends in physical inactivity. Am J Med. 2015;128:e21.

15. Gorzelitz J, Peppard PE, Malecki K, Gennuso K, Nieto FJ, Cadmus-Bertram L. Predictors of discordance in self-report versus device-measured physical activity measurement. Ann Epidemiol. 2018;28:427-31.

16. World Health Organization. Global Physical Activity Questionnaire (GPAQ) Analysis Guide. 2017

17. Bull FC, Maslin TS, Armstrong T. Global physical activity questionnaire (GPAQ): nine country reliability and validity study. J Phys Act Health. 2009:6:790-804

18. Physical Activity Guidelines Committee. Physical Activity Guidelines Advisory Committee Report. Washington DC, US, Department of Health and Human Services; 2008.

19. Baldwin SA, Fellingham GW, Baldwin AS. Statistical models for multilevel skewed physical activity data in health research and behavioral medicine. Health Psychol. 2016;35:552-62.

20. Nobre AA, Carvalho MS, Griep RH, Fonseca MJMD, Melo ECP, Santos IS, et al. Multinomial model and zero-inflated gamma model to study time spent on leisure time physical activity: an example of ELSA-Brasil. Rev Saude Publica. 2017:51:76.

21. King NB, Harper S, Young ME. Use of relative and absolute effect measures in reporting health inequalities: structured review. BMJ. 2012;345:e5774.

22. Bieler GS, Brown GG, Williams RL, Brogan DJ. Estimating model-adjusted risks, risk differences, and risk ratios from complex survey data. Am J Epidemiol. 2010;171:618-23.
23. Graubard BI, Korn EL. Predictive margins with survey data. Biometrics. 1999:55:652-9.

24. Harper S, Lynch CF. Measuring health inequalities. In: Oakes JM, Kaufman JS, editors. Methods in Social Epidemiology. San Francisco: Jossey-Bass; 2006. p. 134-68.

25. Bauman AE, Reis RS, Sallis JF, Wells JC, Loos RJ, Martin BW. Correlates of physical activity: why are some people physically active and others not? Lancet. 2012;380:258-71.

26. Bauman A, Ma G, Cuevas F, Omar Z, Waqanivalu T, Phongsavan P, et al. Cross-national comparisons of socioeconomic differences in the prevalence of leisure-time and occupational physical activity, and active commuting in six Asia-Pacific countries. J Epidemiol Community Health. 2011;65:35-43.

27. Sallis JF, Cerin E, Conway TL, Adams MA, Frank LD, Pratt M, et al. Physical activity in relation to urban environments in 14 cities worldwide: a cross-sectional study. Lancet. 2016:387:2207-17.

28. Owen N, Leslie E, Salmon J, Fotheringham MJ. Environmental determinants of physical activity and sedentary behavior. Exerc Sport Sci Rev. 2000;28:153-8.

29. Williams DR, Mohammed SA, Leavell J, Collins C. Race, socioeconomic status, and health: complexities, ongoing challenges, and research opportunities. Ann N Y Acad Sci. 2010;1186:69-101.

30. Emmons WR, Ricketts LR. College is not enough: higher education does not eliminate racial and ethnic wealth gaps. Fed Reserve Bank St Louis Rev. 2017;99:7-39.

31. Meschede T, Taylor J, Mann A, Shapiro T. "Family achievements?" How a College Degree Accumulates Wealth for Whites and Not For Blacks. Fed Reserve Bank St. Louis Rev. 2017;99:121-37.

32. Marshall SJ, Jones DA, Ainsworth BE, Reis JP, Levy SS, Macera CA. Race/ ethnicity, social class, and leisure-time physical inactivity. Med Sci Sports Exerc. 2007:39:44-51.

33. Farmer MM, Ferraro KF. Are racial disparities in health conditional on socioeconomic status? Soc Sci Med. 2005:60:191-204.

34. Franzini L, Taylor W, Elliott MN, Cuccaro P, Tortolero SR, Janice GM, et al. Neighborhood characteristics favorable to outdoor physical activity: disparities by socioeconomic and racial/ethnic composition. Health Place. 2010;16:267-74

35. Estabrooks PA, Lee RE, Gyurcsik NC. Resources for physical activity participation: does availability and accessibility differ by neighborhood socioeconomic status? Ann Behav Med. 2003;25:100-4.

36. Powell LM, Slater S, Chaloupka FJ, Harper D. Availability of physical activity-related facilities and neighborhood demographic and socioeconomic characteristics: a national study. Am J Public Health. 2006:96:1676-80

37. Giles-Corti B, Donovan RJ. The relative influence of individual, social and physical environment determinants of physical activity. Soc Sci Med. 2002;54:1793-812.

38. Gordon-Larsen $\mathrm{P}$, Nelson MC, Page P, Popkin BM. Inequality in the built environment underlies key health disparities in physical activity and obesity. Pediatrics. 2006:117:417-24.

39. Yancey AK, Ory MG, Davis SM. Dissemination of physical activity promotion interventions in underserved populations. Am J Prev Med. 2006:31:S82-91.

40. Lee RE, Lorenzo E, Heck K, Kohl HW, Cubbin C. Interrelationships of physical activity in different domains: evidence from the geographic research on wellbeing (GROW) study. J Transport Health. 2017;6:538-47.

41. Meyer OL, Castro-Schilo L, Aguilar-Gaxiola S. Determinants of mental health and self-rated health: a model of socioeconomic status, neighborhood safety, and physical activity. Am J Public Health. 2014;104:1734-41.

42. He XZ, Baker DW. Differences in leisure-time, household, and work-related physical activity by race, ethnicity, and education. J General Intern Med. 2005:20(3):259-66.

43. Holder M. African American Men's decline in labor market status during the great recession. In: African American Men and the Labor Market during the Great Recession. New York: Palgrave Macmillan; 2017.

44. Couch KA, Fairlie R. Last hired, first fired? Black-white unemployment and the business cycle. Demography. 2010;47:227-47.

45. Yusuf S, Wittes J, Probstfield J, Tyroler HA. Analysis and interpretation of treatment effects in subgroups of patients in randomized clinical trials. JAMA. 1991;266:93-8.

46. Petticrew M, Tugwell $P$, Kristjansson $E$, Oliver $S$, Ueffing $E$, Welch V. Damned if you do, damned if you don't: subgroup analysis and equity. J Epidemiol Community Health. 2012;66:95-8. 
47. Chetty R, Hendren N, Jones MR, Porter SR. Race and economic opportunity in the United States: an intergenerational perspective. Natl Bur Econ Res. 2018:w24441.

48. Dowd JB, Hamoudi A. Is life expectancy really falling for groups of low socio-economic status? Lagged selection bias and artefactual trends in mortality. Int J Epidemiol. 2014;43:983-8.

49. Prince SA, Adamo KB, Hamel ME, Hardt J, Connor GS, Tremblay M. A comparison of direct versus self-report measures for assessing physical activity in adults: a systematic review. Int J Behav Nutr Phys Act. 2008;5:56.

50. Tucker JM, Welk GJ, Beyler NK. Physical activity in U.S.: adults compliance with the physical activity guidelines for Americans. Am J Prev Med. 2011;40:454-61

51. Rebustini F, Balbinotti MAA, Ferretti-Rebustini REL, Machado AA. Sport psychometry, participants and invariance: a critical review. J Phys Educ. 2016;27:e2760.

52. Braveman PA, Cubbin C, Egerter S, Williams DR, Pamuk E. Socioeconomic disparities in health in the United States: what the patterns tell us. Am J Public Health. 2010;100(Suppl 1):S186-96.

53. Holtermann A, Krause N, van der Beek AJ, Straker L. The physical activity paradox: six reasons why occupational physical activity (OPA) does not confer the cardiovascular health benefits that leisure time physical activity does. Br J Sports Med. 2018;52:149-50.

54. Li J, Loerbroks A, Angerer P. Physical activity and risk of cardiovascular disease: what does the new epidemiological evidence show? Curr Opin Cardiol. 2013;28:575-83.

55. White RL, Babic MJ, Parker PD, Lubans DR, Astell-Burt T, Lonsdale C. Domain-specific physical activity and mental health: a meta-analysis. Am J Prev Med. 2017:52:653-66.

Ready to submit your research? Choose BMC and benefit from:

- fast, convenient online submission

- thorough peer review by experienced researchers in your field

- rapid publication on acceptance

- support for research data, including large and complex data types

- gold Open Access which fosters wider collaboration and increased citations

- maximum visibility for your research: over $100 \mathrm{M}$ website views per year

At $\mathrm{BMC}$, research is always in progress.

Learn more biomedcentral.com/submissions 